$1 \mathrm{DJ}$ Pierson. Tumors and cysts of the mediastinum. In Murray JF, Nadel JA, eds. Textbook of respiratory medicine. Philadelphia: WB Saunders Company, 1994; pp 2278-89. 2 DJ Pierson. Disorders of the mediastinum. General principles and diagnostic approach. In: Murray JF, Nadel JA eds. Textbook of respiratory medicine. Philadelphia: WB Saunders Company, 1994; pp 2235-49.

3 Dooms GC, Hricak H. Radiologic imaging modalities, including magnetic resonance, for evaluating lymph nodes. West $₹$ Med 1986; 114: 49-57.

4 Khan J, Akhtar M, von Simmer WN, Bouchama A, Bazarbashi M. CT-guided fine needle aspiration biopsy in the bashi M. CT-guided fine needle aspiration biopsy in the 1329-32.
5 Hanania N, Hoffstein V. Tuberculosis presenting with generalized lymphadenopathy, pulmonary infiltrates and bone destruction in a young man. Arch Intern Med 1993 153: $1265-7$.

6 Watts RA, Paice EW, White AG. Spontaneous fracture of the sternum and sternal tuberculosis. Thorax 1987; 42 984-5.

7 Kaplan G, De Gennes C, Le Charpentier Y. Tuméfaction sternale douloureause et fébrile chez une martiniquaise. Ann Med Intern 1990; 141: 71-6.

\title{
Acute pulmonary oedema in late pregnancy
}

\author{
D O'Mahony, G Hendry, P Strube, M Jonas, D Sumner
}

\section{Case history}

An 18-year-old Asian primigravida, 34 weeks pregnant, presented to hospital with mild-tomoderate pregnancy-induced hypertension (blood pressure $160 / 105 \mathrm{mmHg}$ ) and $1+$ proteinuria on urinalysis. Antenatal assessments had been hitherto normal. She was treated with intravenous hydralazine without success. Methyldopa was added to her therapy, but her blood pressure remained elevated and proteinuria deteriorated to $2+$. On the third hospital day, the patient became severely breathless over a period of four hours. On examination, she was moderately distressed and tachpnoeic ( 34 beats/min) and had a gallop rhythm with diffuse fine inspiratory crackles in both lung bases. A chest radiograph confirmed appearances of pulmonary oedema.

Wycombe General Hospital, Queen Alexandra Rd, High

Wycombe, Bucks, HP11 2TT, UK

Department of

Medicine

D O'Mahony

G Hendry

Department of

Anaesthetics

P Strube

M Jones

Department of

Obstetrics and

Gynaecology

D Sumner

Accepted 29 March 1995

\section{Investigation results}

- arterial blood gas analysis on room air: $\mathrm{pO}_{2}$ $9.3 \mathrm{kPa}, \mathrm{pCO}_{2} 4.1 \mathrm{kPa}, \mathrm{pH} 7.46$, actual $\mathrm{HCO}_{3}$ $22.1 \mathrm{mmol} / \mathrm{l}, \mathrm{O}_{2}$ saturation $94.9 \%$

- ECG: sinus tachycardia only

- chest radiograph: normal cardiac size and contour, signs of bilateral lower zone parenchymal soft tissue shadowing and Kerley B lines consistent with pulmonary oedema

- plasma creatinine $66 \mu \mathrm{mol} / \mathrm{l}$, sodium $140 \mathrm{mmol} / 1$, potassium $3.9 \mathrm{mmol} / 1$, serum albumin $29 \mathrm{~g} / 1$, total serum protein $53 \mathrm{~g} / 1$

- echocardiography (M-mode and 2-D); hyperdynamic left ventricle not hypertrophied or dilated. Left atrium slightly dilated $(3.4 \mathrm{~cm})$. No evidence of valvular disease or septal defect. Mild mitral regurgitation noted on colour flow and Doppler flow analysis

- Free T3 6.1 pmol/1 (normal 4.3-7.6 pmol/1; TSH 0.14 mIU/1 (normal 0.14-3.45 mIU/1)

\section{Questions}

1 Suggest three cardiovascular causes of acute pulmonary oedema in late pregnancy?

2 What is the most likely cause of pulmonary oedema?

3 What is the recommended management?

4 What is the prognosis? 
Answers

QUESTION 1

The cardiovascular causes of acute pulmonary oedema in late pregnancy are listed in box 1 .

\section{QUESTION 2}

Pregnancy-induced hypertension.

\section{QUESTION 3}

The first line treatment is intravenous frusemide $40 \mathrm{mg}$ or bumetanide $1 \mathrm{mg}$ as a bolus dose. The aim is to achieve a diuresis of $2-31$ in the first 24 hours of diuretic therapy. A Swan-Ganz catheter is desirable in severe pre-eclamptic patients who develop pulmonary oedema antepartum. This allows the clinician to differentiate between fluid overload, left ventricular dysfunction and non-hydrostatic pulmonary oedema, the management of each being different.

Right atrial pressure $\left(16 \mathrm{cmH}_{2} \mathrm{O}\right)$, pulmonary artery pressure $(42 / 16 \mathrm{mmHg})$ and pulmonary capillary wedge pressure (PCWP; $24 \mathrm{mmHg}$ ) were all raised in this case. The serum albumin concentration dropped to a nadir of $27 \mathrm{~g} / 1$ (total protein $52 \mathrm{~g} / \mathrm{l}$ ) and the plasma colloid oncotic pressure (COP) was calculated as $18.9 \mathrm{mmHg}$ (normally approximately $25 \mathrm{mmHg}$ ). Thus, a lowered plasma oncotic pressure and a raised PCWP both contributed to pulmonary interstitial fluid accumulation and eventually pulmonary oedema. PCWP was reduced by a combination of intravenous frusemide and isosorbide dinitrate infusion. COP may be increased by infusing $200 \mathrm{ml}$ of $20 \%$ albumin after achieving a satisfactory diuresis. The intravenous frusemide and dinitrate helped reduced systemic arterial blood pressure and reverse pulmonary oedema sufficient to proceed to emergency caesarian section, which is the most important measure in resolving the pregnancyinduced hypertension.

The patient was delivered of a live, but low birth weight infant $(2.2 \mathrm{~kg})$ without signs of neonatal distress. Postoperatively, the patient's blood pressure and PCWP settled to normal levels within 24 hours with the isosorbide dinitrate infusion, which was continued for 48 hours after delivery. The diastolic blood pressure became elevated again $(100-110$ $\mathrm{mmHg}$ ) after stopping the dinitrate infusion and the patient was treated with oral slowrelease nifedipine $20 \mathrm{mg}$ bid. This therapy was gradually reduced and eventually stopped after three weeks.

\section{QUESTION 4}

The prognosis is generally excellent with prompt diuretic therapy and delivery, once the pulmonary oedema is controlled.

\section{Discussion}

Unexpected acute pulmonary oedema in pregnant women is uncommon and often generates suspicions of undiagnosed valvular heart disease, acute pulmonary embolism, thyrotoxic heart failure and peripartum cardiomyopathy.
Cardiovascular causes of acute pulmonary oedema in late pregnancy

- rheumatic valvular heart disease

- congenital heart disease

- pregnancy-induced hypertension

- peripartum cardiomyopathy

- hypertensive heart failure

- thyrotoxic heart failure

- beta-agonist tocolytic therapy

Box 1

The latter in particular is worrying for clinicians, since it carries a grave prognosis in approximately $25-50 \%$ of patients. ${ }^{1}$ However, peripartum cardiomyopathy usually occurs between the last month of pregnancy and the first six months postpartum, making it an unlikely diagnosis in this patient. Pregnancyinduced hypertension is a seldom-mentioned cause of acute pulmonary oedema in previously healthy women, and should be considered in the differential diagnosis in all women with pregnancy-induced hypertension who become suddenly dyspnoeic as this case illustrates.

The patient did not receive intravenous fluid prior to the onset of pulmonary oedema, nor any beta-agonist tocolytics, which occasionally precipitate pulmonary oedema. ${ }^{2}$ Beta-agonists stimulate the renin/angiotensin pathway and antidiuretic hormone release, with resultant sodium and water retention. Pulmonary oedema may occur particularly if beta-agonists (most commonly salbutamol and ritodrine) are administered in balanced salt solutions as opposed to $5 \%$ dextrose. The salt and water positive balance with tocolytics is independent of concurrently administered betamethasone or dexamthasone (to prevent foetal respiratory distress syndrome).

Sabai et al reported pulmonary oedema in $2.9 \%$ of a series of almost 1300 women with severe pre-eclampsia-eclampsia, ${ }^{3}$ nearly $75 \%$ of whom developed pulmonary oedema postpartum. In this series, patients with pulmonary oedema caused by pregnancy-induced hypertension were generally older multigravidas and more likely to have had long-standing hypertension. The pathophysiology of pulmonary oedema resulting from pregnancyinduced hypertension is not completely understood, but studies by Cotton $e t a l^{4}$ and Benedetti et $a{ }^{\bar{T}}$ have noted abnormal COP-PCWP gradients in patients developing pulmonary oedema caused by pregnancyinduced hypertension. Benedetti et al, described 10 patients with this condition, five of whom had abnormal COP-PCWP gradients. Among the other five patients, pulmonary oedema was related to increased pulmonary capillary permeability in three, and left ventricular failure in two. We calculated the COP to be $18.9 \mathrm{mmHg}$ in our patient. ${ }^{6}$ Given that the PCWP (24 mmHg) exceeded this level of COP, it is likely that the reduced plasma albumin level, in addition to the raised afterload caused by the increased systemic vascular resistance 
(as reflected by the marked diastolic hypertension), both contributed significantly to the development of pulmonary oedema. Cotton et $a l$ recommend a nitrate infusion in addition to conventional intravenous doses of frusemide to treat pulmonary oedema caused by pregnancyinduced hypertension. Afterload reduction with hydralazine or sodium nitroprusside may be necessary if intravenous boluses of frusemide and nitrate infusion are ineffective.

It is not clear from the literature whether albumin infusion has a role in the management of pulmonary oedema related to pregnancyinduced hypertension. However, where patients manifest heavy proteinuria as in this case, and where the COP-PCWP gradient can be clearly shown to be negative, it seems

1 Homans DC. Peripartum cardiomyopathy. $N$ Engl $f$ Med 1985; 312, 1432-7.

2 Watson NA, Morgan B. Pulmonary oedema and salbutamol in preterm labour. Case report and literature review. $\mathrm{Br} \mathscr{F}$ in preterm labour. Case report and

3 Sibai BM, Mabie BC, Harvey CJ, Gonzalez AR. Pulmonary edema in severe preeclampsia-eclampsia: analysis of 37 cases. Am $f$ Obstet Gynecol 1987; 156: 1174-9.

4 Cotton DB, Gonik B, Dorman K, Harrist R. Cardiovascula alterations in severe pregnancy-induced hypertension: rela tionship of central venous pressure to pulmonary capillary wedge pressure. Am $\mathcal{Y}$ Obstet Gynecol 1985; 151: 762-4. reasonable to correct hypoalbuminaemia, particularly levels less than $30 \mathrm{~g} / 1$. The infusion of $200 \mathrm{ml}$ of $20 \%$ albumin in this patient coincided with intravenous frusemide boluses and isosorbide dinitrate infusion. Thus, it is not certain to what degree albumin infusion may have helped improve the pulmonary oedema. Further experience of managing this condition will no doubt clarify this point.

\section{Final diagnosis}

Pregnancy-induced hypertension resulting in acute pulmonary oedema.

Keywords: pregnancy-induced hypertension, acute pulmonary oedema

5 Benedetti TJ, Kates R, Williams V. Hemodynamic observations in severe preeclampsia complicated by pulmonary tions in severe preeclampsia complicated by
edema. Am $₹$ Obstet Gynecol $1985 ; 152: 330-4$.

6 Guyton AC. Textbook of medical physiology, 6th edn. 6 Guyton AC. Textbook of medical physiology,

7 Cotton DB, Jones MM, Longmire S, Dorman KF, Tessem $\mathrm{J}$, Joyce TH. Role of intravenous nitroglycerin in the treatment of severe pregnancy-induced hypertension complicated by pulmonary edema. Am $\mathcal{F}$ Obstet Gynecol 1986 154: 91-3. 